\title{
Tackling Complex Social Challenges within Neoliberal Constraints: The Context Shaping 'Intellectual Quality of Life' (iQoL) in a Canadian University Context
}

\author{
Suzanne Huot ${ }^{1, *} \mathbb{C}^{\mathbb{C}}$, Jocelyn McKay ${ }^{2}$, Skye Barbic ${ }^{1,3}$, Alison Wylie ${ }^{4}$, Dominique Weis ${ }^{5}$, \\ Sarah Bean Sherman ${ }^{5}$ and Liisa Holsti ${ }^{1}$ \\ 1 Department of Occupational Science and Occupational Therapy, Faculty of Medicine, University of British \\ Columbia, Vancouver, BC V6T 1Z4, Canada; skye.barbic@ubc.ca (S.B.), liisa.holsti@ubc.ca (L.H.) \\ 2 Designing for People, University of British Columbia, Vancouver, BC V6T 1Z4, Canada; \\ dfp-facilitator@dfp.ubc.ca \\ 3 Centre for Health Evaluation Outcome Sciences, University of British Columbia, \\ Vancouver, BC V6T 1Z4, Canada \\ 4 Department of Philosophy, Faculty of Arts, University of British Columbia, Vancouver, BC V6T 1Z4, Canada; \\ alison.wylie@ubc.ca \\ 5 Department of Earth, Ocean and Atmospheric Sciences, Faculty of Science, University of British Columbia, \\ Vancouver, BC V6T 1Z4, Canada; dweis@eoas.ubc.ca (D.W.), ssherman@eoas.ubc.ca (S.B.S.) \\ * Correspondence: suzanne.huot@ubc.ca
}

Received: 31 January 2020; Accepted: 14 March 2020; Published: 17 March 2020

check for updates

\begin{abstract}
The contemporary academic environment in Canada has undergone reorganization based on neoliberal principles, and has increased attention focused on the importance of supporting interdisciplinary initiatives to address complex problems affecting global society. The purpose of our study was to examine the experience of people participating in a specific university-funded interdisciplinary research initiative. As there is a strong emphasis within this program on reporting on the outcomes of the funding that supports interdisciplinary collaboration, our aim was to explore how participation may shape one's intellectual quality of life (iQoL) and how one's iQoL could be conceptualized and understood. Using a pragmatic constructivist case study, focus group and individual interviews were undertaken with 30 participants involved with university-funded interdisciplinary research teams. Findings illustrate that their iQoL was shaped by their capacity to engage in and achieve what they viewed as their core work and its outcomes. Related sub-themes addressed the social and relational climate, institutional environment and structure, and expectations and resources. We argue that further development of iQoL as a unique construct is required to adequately measure the full range of people's experiences in academia, particularly when aiming to address 'wicked' social and global problems within a predominantly neoliberal context.
\end{abstract}

Keywords: academia; innovation; interdisciplinary; neoliberal; quality of life

\section{Introduction}

In an increasingly globalized world social, political, environmental, and other complex challenges, including climate change, health pandemics, and global refugee crises, cannot be easily solved [1]. Traditional university structures organized by disciplines and faculties spread across campuses can result in physical and intellectual separations and silos that generate first-order science [2] and make it more challenging to conduct the innovative research needed to address complex problems. There is recognition within academia, however, that interdisciplinary connections are required to solve 
'wicked problems' [3,4]. Dentoni and Bitzer [3] characterized wicked problems, a term originally coined by Rittel and Weber [5], as changing over time, having scientifically uncertain causes and effects, and involving value conflicts among different stakeholders in society. Wicks and Jamison [1] further explained that the problems are described as wicked not because they are inherently morally problematic, but instead because they have defied traditional attempts to solve them. Tackling such wicked problems thus requires innovation and a whole system perspective [6].

In the last decade, there have been diverse initiatives undertaken by Canadian universities to build interdisciplinary bridges in an effort to support design thinking [7], social transformation [8], and other innovative approaches to knowledge generation and mobilization. At the same time, increasing attention has been paid to the ongoing reorganization of academia in line with neoliberal principles [9]. Specifically, Cannizzo has outlined the "managerialisation of university governance" to illustrate what he described as the role of tactical evaluations in shaping the experience of "everyday neoliberalism in academia" [10] (p. 77). The potential negative implications of the neoliberal reconfiguration of universities were examined by Berg and colleagues [11] who suggested that the use of ranking and audit systems can contribute to increased levels of stress and anxiety among university employees. Similarly, Hawkins and colleagues [12] examined the daily and corporeal experiences of the corporatization of academia for graduate students and found that the ideal of work-life balance was perceived as being impossible to achieve, with attention to self-care, for instance, being constructed as counterproductive to academic success.

A paradox is created by the expectation that researchers work across disciplines to generate innovative solutions to address wicked problems in global society, while at the same time being expected to govern themselves in line with managerial expectations related to traditional measures of academic productivity [13]. The study described herein was sparked by the intersection of interdisciplinary initiatives and neoliberal technologies [14] at one specific Canadian research-intensive university (the University of British Columbia). With pressures on academic faculty, staff, and students being higher than ever [15], our interdisciplinary team, coming from the Faculties of Medicine, Arts, and Science sought to develop an understanding of how occupational expectations to address complex issues, while obtaining competitive funding, and producing outcomes on relatively short-term timelines (e.g., annual evaluation and funding cycles) were experienced by people working in academia. Specifically, we aimed to use this gained understanding to develop a concept characterizing their intellectual quality of life (iQoL).

Quality of life surveys and indices are a well-established staple of national and international data gathering programs aimed at assessing the well-being of citizens and communities in terms that complement economic measures [16]. The quality of life literature offers nuance to help better understand different facets of this construct, or different forms of quality of life, such as health-related quality of life, and quality of academic worklife $[17,18]$. Our paper contributes novel insight into a broader intellectual perspective on quality of life by asking 'How is iQoL conceptualized by university members?' We explored this question among faculty, staff, postdoctoral fellows, graduate students, and administrators involved with interdisciplinary research teams funded to address complex issues requiring innovative approaches. Within the Canadian research-intensive university where the study was conducted, an annual funding competition is held that provides support for groups conducting interdisciplinary research [19]. The aim of the program is to foster increased collaboration that will make teams of interdisciplinary scholars more innovative and more competitive in accessing external funding. Applications to this competition must outline clear, measurable objectives and include a detailed outcomes report from previously obtained funding that is used to assess team success (e.g., numbers of team grants and co-authored publications). While the aim of the funding is to "address key societal and cultural problems, and work together to solve challenges that transcend traditional boundaries" [19], expected outcomes focus mainly on increased research productivity. We sought to understand how participants' experiences of participating in these interdisciplinary research collaborations, largely governed through a neoliberally-informed managerial approach, shaped their iQoL. 


\section{Methods}

We adopted a pragmatic constructivist case study approach to enable us to sort, manage, and interpret data to convey applicability of the findings [20,21]. Qualitative methods and inductive reasoning were used to collect and analyze data that would support a "rich holistic description that illuminates one's understanding of the phenomena", meaning participants' description of iQoL [21] (p. 10). We used both individual and focus group interviews to enhance data richness [22]. Individual interviews are the most common method of qualitative data collection, used to capture participants' attitudes, beliefs, thoughts, and knowledge with respect to a particular topic [22]. Focus groups are a useful exploratory method ideal for stimulating discussion and debate among participants, facilitating the identification of key issues related to a theme, and highlighting different perspectives on an issue during a single meeting [23-25]. Both methods enable the co-construction of findings between researchers and participants to support a better understanding of how participants make sense of their experiences [26].

After obtaining institutional ethics approval (H18-02323, University of British Columbia), we recruited participants from interdisciplinary research teams that had received university funding during at least one annual cycle. To be included in the study, participants had to: be 19 years of age or older; a member of a university-funded interdisciplinary research team; and willing and able to read and respond in English, to participate in an interview (individual or focus group), and to provide informed consent. Four individual interviews and five focus groups were conducted. Interviews were conducted with people who wanted to participate but who were unavailable to attend a focus group session. A total of 30 participants were recruited and the demographic characteristics are summarized in Table 1.

Individual and focus groups interviews lasted approximately 30-90 min each and were conducted using a semi-structured approach. Questions addressed participants' interpretation of the concept of iQoL, their descriptions of what positively and negatively contributed to their experience of iQoL, and what factors and resources were required to enhance iQoL.

The individual and focus group interviews were all audio-recorded and transcribed verbatim. Following the analysis process outlined by Braun and Clarke [27], six phases of thematic analysis were undertaken. First, all authors read and re-read the full data set in its entirety to familiarize themselves with the transcripts. Second, the first two authors (SH and JM) then each generated a list of initial codes by independently conducting a line-by-line analysis of each transcript. This process entailed attaching codes to each section of text. The full team then met to review the full list of codes that was developed to ensure that these resonated with each researcher's individual review of the transcripts and that no important insights were absent. These early stages of analysis resulted in the development of 522 unique codes. Third, these codes were placed alphabetically into an Excel spreadsheet, reviewed, and discussed in order to search for themes. Throughout the process codes were moved into different columns to begin developing themes. Fourth, the themes were reviewed in relation to the data and were further refined (e.g., creating or collapsing sub-themes). Fifth, themes were named and defined and the relationship between them was outlined. Finally, as part of 'producing the report' the themes were described with supporting examples drawn directly from the data. 
Table 1. Demographic characteristics of the participant sample.

\begin{tabular}{|c|c|c|}
\hline Characteristic & & Value \\
\hline \multirow[t]{7}{*}{ Age (Years) } & $19-24$ & 1 \\
\hline & $25-34$ & 8 \\
\hline & $35-33$ & 6 \\
\hline & $45-54$ & 7 \\
\hline & $55-64$ & 3 \\
\hline & $65-74$ & 2 \\
\hline & $75+$ & 1 \\
\hline Gender & Female/Male/Other & $13 / 15 / 0$ \\
\hline \multirow[t]{6}{*}{ Years at current institution } & $<2$ & 5 \\
\hline & $2-4$ & 8 \\
\hline & $5-9$ & 5 \\
\hline & $10-14$ & 4 \\
\hline & 15-19 & 2 \\
\hline & $>20$ & 4 \\
\hline \multirow[t]{6}{*}{ Current academic rank } & Instructor & 1 \\
\hline & Senior Instructor & 1 \\
\hline & Ass. Prof & 5 \\
\hline & Assoc. Prof & 2 \\
\hline & Prof & 9 \\
\hline & Other (Grad/Postdoc/Staff) & $12(4 / 3 / 5)$ \\
\hline \multirow[t]{4}{*}{ Years in interdisciplinary research team } & $<6$ months & 6 \\
\hline & 6 months- 1 year & 6 \\
\hline & 1 year -2 years & 8 \\
\hline & $>2$ years & 6 \\
\hline \multirow[t]{9}{*}{ Faculty } & Applied Science & 3 \\
\hline & Arts & 3 \\
\hline & Forestry & 1 \\
\hline & Graduate Studies & 1 \\
\hline & Medicine & 2 \\
\hline & Pharmaceuticals & 1 \\
\hline & Science & 13 \\
\hline & Land and Food Systems & 6 \\
\hline & $\begin{array}{l}\text { Institute for Resources, Environment, } \\
\text { and Sustainability }\end{array}$ & 1 \\
\hline
\end{tabular}

\section{Results}

Our analysis of the transcripts led to the identification of a primary theme and related sub-themes. When describing what iQoL meant to them, across participants there was a strong, repeated emphasis placed on having the freedom to engage in work that they described as being core to their respective roles. Their capacity to engage in what they envision as their core work and to achieve the desired outcomes was described as being central to having a positive sense of iQoL. Conversely, factors that pulled participants away from their core work were identified as having a negative impact on their iQoL. Participants who described how the broader neoliberal academic context further shaped their iQoL identified related sub-themes that either supported or hindered one's capacity to engage in their perceived core work. These sub-themes included the social and relational climate, the institutional 
environment and structure, as well as expectations and resources. Each of these sub-themes were described as having positive and negative characteristics, and as being reciprocally related to one another, forming a broader web of influence contextualizing one's iQoL for better or for worse (Figure 1).

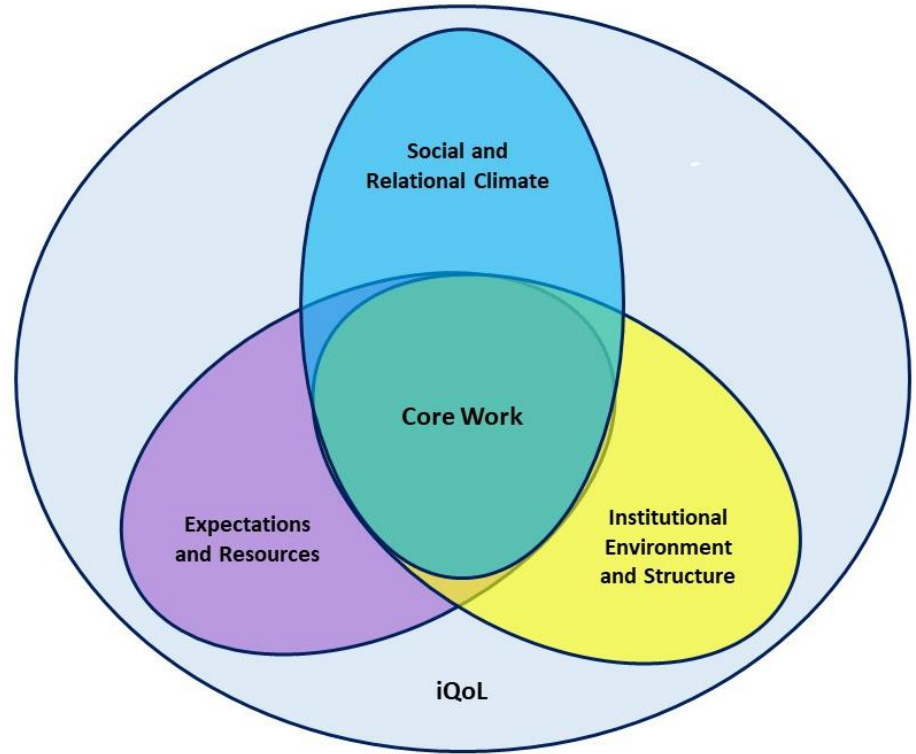

Figure 1. Conceptual representation of the factors influencing intellectual quality of life (iQoL).

\subsection{Core Work and Its Outcomes}

When initially asked "What does iQoL mean to you?" participants struggled to give a coherent or concise response, but instead reflected and described what we have interpreted as this primary theme, that of having the freedom to conduct what one perceives as one's core work and to achieve its intended outcomes. The challenge in immediately articulating a succinct response to our question may be due to the introduction of this novel concept to participants who had not considered it in advance of the data collection session. While our aim was to inductively develop this concept from the data, participants seemed to assume an understanding of this concept existed and that we were interested in their familiarity with it. This led us to clarify that we had no operational definition of iQoL and were curious what it meant to them. The following citations outline some of the initial responses to our opening question:

My first thought is, I have no idea. Like it could mean so many different things and I just don't even know the vague scope of what you're thinking of.

Challenge, fun, provocative. I realize you didn't say, 'Say the word that comes to mind,' but that's what you're getting.

As the conversations continued, more nuanced thoughts were shared that informed this primary theme. Core work relates to participants' holistic and subjective understanding of their greater purpose within academia, characterized by various forms of intellectual engagement that did not always reflect the diversity of tasks they were assigned as part of their employment. Participants described this core work in part through the ways they discussed what they perceived to be the central purpose of their occupation, including generating and disseminating knowledge through both research and teaching. While iQoL itself proved challenging to define, participants shared their sense of what it felt like to experience positive iQoL, such as in the following quotation: 
There's a, I don't have the words for it, but this feeling of figuring stuff out and getting it right, and I use words like everything clicks into place after the head hurt explode part.

The positive aspects of iQoL discussed most frequently by participants related to forms of meaningful engagement. This encompassed positive engagement not only with colleagues, peers, and students, but also engagement with ideas through which people experienced intellectual challenge and stimulation that served as a form of motivation. Some participants also mentioned the importance of feeling that their work was recognized and valued.

Descriptions of iQoL were highly experiential, getting less at what it is and more at how it feels:

High iQoL is being excited about what you're working on, having new ideas, a flood. Having people to talk to with those ideas about. Having opportunities to get involved with ideas and people. Having to challenge oneself. To stretch, to keep creating that environment, or reaching a place where you can investigate those ideas. Learn new stuff.

Feelings associated with iQoL, whether positive or negative, that were expressed included motivation and excitement about opportunities created by interdisciplinary collaboration, but also the apathy and frustration that could stem from things not going as anticipated and people feeling they had wasted time. Some participants spoke to feelings of stress and guilt stemming from challenges in balancing multiple responsibilities (both personal and professional).

While participants shared enthusiastic descriptions of what experiencing positive iQoL was like, many explained that engaging in one's core work, which appeared to be the main contributor to high iQoL, did not automatically occur and was something one had to consciously make time for. One participant shared the following: "By the time when you're engaged in what feels like your core activities or core interests, it feels like high quality time. So trying to get that to be a larger fraction of the day is our pursuit."

Yet in trying to manage one's time to support positive iQoL, it should be noted that this did not simply refer to putting one role ahead of another. Participants described experiencing iQoL in relation to more than just a single aspect of their employment. It was not viewed as being characteristic of either research or teaching for instance, but more as a sense of engaging in the core aspects of their varied roles. One participant clarified this further by explaining how various aspects of one's work could come together to support a strong sense of iQoL:

I think [intellectual] quality of life, to me, means that there is something in the future that remains challenging and gives you a reason to go to work every day... So that means teaching courses that are stimulating, that means having grad students that are working on stuff that's stimulating and that's moving the needle of science forward.

Likewise, certain aspects of respective roles (e.g., research or teaching) could also contribute to an experience of poor iQoL if it detracted from what was perceived as being core to that endeavor. The two following examples illustrate how needing to spend time on tasks that were not perceived as supporting one's core work hindered iQoL:

Death of a thousand cuts, but I have just worked 12 hours and all of it is utterly frustrating and non-intellectual crap. 
But I'm focusing too much ... I've drifted too much into administrative factors and not off into the inherent or intrinsic nature of the work.

Several specific examples were shared, such as needing to respond to several email messages on a daily basis that could be very time consuming and not contribute to the outcomes participants' hoped to achieve through their core work. Thus, participants recognized the influence of broader spatial and temporal dimensions contextualizing their day-to-day experiences within academia. For example, the need for time to think, whether on one's one or with others, was viewed as crucial to core work:

Uninterrupted time to explore ideas whether that's with colleagues, with diverse thinkers or on your own, but kind of not having the clock running or a very short window to be able to explore ideas and think through things in an open ended way where you don't necessarily have to have a bunch of outcomes or deliverables but just being able to think and explore and bounce ideas off each other, that's really important.

Aspects related to space and time were described as contributing either positively or negatively to their ability to engage in their core work, and hence to achieve a stronger subjective experience of iQoL.

\subsection{Social and Relational Climate}

As intellectual engagement in one's core work was described as being central to the experience of positive iQoL, factors supporting or detracting from one's capacity to engage in that work were described as also influencing one's iQoL. Participants spoke to the social and relational climate within which their work was embedded. This sub-theme captures aspects of the inter-personal work environment. Participants discussed the people they interacted with in various roles, describing their communities or networks of co-workers. The nature of daily social interactions was described as having an important influence on their experience of iQoL.

Certainly when the social and relational climate was described positively, the work environment was viewed as being conducive to enhanced iQoL, as was described by one participant: "Good colleagues, I'm lucky I'm in a very functional unit. We love each other. Anyone would drop anything to help each other. Open and transparent [department] head. [That makes a] Huge difference in iQoL." (T6). Referring specifically to the types of social interactions that were supported through the interdisciplinary research teams, one participant explained the 'magic' that can happen when afforded the opportunity to interact with peers:

It's being able to be with peers at that 60 year old luminary level and just rub elbows to sparks flying and good stuff happening, it needs to be peers with that respect. But when it clicks, when you get that magic of just ideas pop and building on each other, that makes a day, it's so exciting.

The data were rich with numerous examples of ways that a positive, supportive, and invigorating inter-personal climate could support iQoL by making engagement in one's core work more meaningful and effective.

Also present within the data, however, were nearly as many descriptions of ways that a negative social and relational climate could stifle iQoL. These negative experiences could stem, on the one hand from a lack of inter-personal interactions resulting from some of the more solitary aspects of academic work, and on the other, to unsafe work environments characterized by bullying and harassment. The following example highlights one among several that were shared to illustrate ways that the social and relational climate was not always supportive of positive iQoL: 
I think that it comes back to the isolation that if you're the only one in your unit or there's very few people then you don't have anyone to talk to, you're isolated, and all the expectations and burdens of that position, instead of being spread across multiple people they're on one or a few people.

The social and relational climate was understood as being influenced by the broader institutional environment and structure within which it was embedded.

\subsection{Institutional Environment and Structure}

Extending beyond the immediate social and relational climate shaping the participants' experiences were aspects related to the sub-theme of the broader institutional environment and structure. Participants spoke to specific policies and procedures of institutions, as well as to the more general culture or expected norms characterizing academia. While many discussed the university specifically, others also referred to other related institutions, such as funding bodies or affiliated research institutions. Overall, participants expected institutions to support and respect the core work that was being done and to acknowledge its outcomes. Within the data, there were examples of how academia was often experienced as a game that had to be played and, ideally won, and the university's role in this game was often criticized, such as in the following example:

Feeling like there's equitable support across disciplines. So in the sense of like looking at the humanities and looking at the sciences and seeing those sometimes pitted against each other or looking at ... So for me a quality of life would not be feeling like one discipline is less worthy than others. I think we pretty much achieve that but I feel like not always in terms of the way resources are distributed. Having the freedom to sort of explore in those fields which aren't necessarily as heavily funded as others would be an example of quality.

The emphasis on productivity and the need to quantify one's productivity for the institution was particularly lamented. One participant addressed the time burden such expectations created: "there's a lot of quantification that goes on and that is time spent in what I will call low quality activities" (T5), such as reformatting one's CV for different funding competitions. The instability of funding, and of internal funding in particular, was also described as fueling pressure and competition, possibly at the expense of the quality and sustainability (e.g., longer term planning) of the research being conducted. For instance, one participant explained that "as you get kind of sucked into the treadmills of productivity, you might lose a bit of that focus in terms of just doing what you can based on what's available."

Nevertheless, there was also recognition of ways that the university environment could and did support iQoL, such as in the following example:

So there's all kind of bureaucratic crap that my current life involves which I would say is not contributing to my iQoL and in fact actively tearing it down. And then there's things like talking about research ideas with my grad students and digging in to the point where I literally get a headache and all the pieces come together, and then by the end, we're like: 'Yes! We figured this thing out!' And then there's this feeling of complete and total joy.

Two key ways that participants mentioned institutions contributing toward positive iQoL were through the provision of funding to support their core work, such as start-up funds for a new faculty, as well as the hiring of highly qualified staff. In addition to the institutional environment and structure, the next sub-theme of 'expectations and resources' had an important impact on iQoL. 


\subsection{Expectations and Resources}

While many of the factors described by participants as influencing their iQoL referred to subjective or experiential characteristics of one's daily experiences in the academy, participants also spoke to the importance of more tangible resources for supporting iQoL. While the notion of 'expectations' in many ways is also subjective, participants described the ways expectations upon them were increasingly being quantified. Participants also spoke to the diverse forms of expectations they faced from multiple stakeholders (e.g., the institution itself, their departments, academic journals, professional societies). The high expectations participants felt were held of them, and that they held of themselves contributed to an ongoing pressure to advance their core work. Yet while this was motivating for some, paradoxically it was contextualized within an environment often characterized by a lack of certainty, stability, and security, as expressed in the following illustrative quotations.

If money were to come a little easier, like if I knew I had exactly $\mathrm{N}$ dollars every year, then that would help a lot, because then I would know I could hire exactly so many grad students and that sort of access would be more desirable from my point of view.

Insecurity. Like in terms of am I going to have a job next year? Am I going to be able to pay my groceries?

The expectations of maintaining a successful research program were experienced as being limited to a certain extent by a lack of committed resources and an overly bureaucratic system. One participant shared a particularly benign example to express how what some referred to in one focus group as "administrivia" detracted from one's core work and hindered iQoL: "Fill out the form to get new pencils and you get it signed by your, you know, I don't know, VP research."

The need for dedicated and quality support was reiterated across focus group discussions and is well summarized by the following excerpt:

We need more professional staff to take care of things that is in their professional expertise so that I can spend my time teaching and researching and having amazing moments while somebody else manages projects. We have some of those amazing professional staff in this room but we tend to fight tooth and nail to get them and so I think that, that is something that for me and I think for projects that I've been involved in has really made the difference. If I have highly qualified professional staff who love what they do, and who also have their own quality of life, then that makes the whole enterprise so much more fun and successful and less stressful. [ ... ] downloading of the clerical work onto faculty is like the death of the university."

Expending resources, including time, space, and energy on tasks that could simply be eliminated by removing expectations that they be completed, or delegated if necessary to complete, was perceived by participants to be a waste of their intellectual capacity and potential.

Participants' discussions about their experiences of iQoL highlighted the ways that inter-related aspects of the broader context, including the social and relational climate, institutional environment and structure, and expectations and resources, shaped their capacity to engage in what they perceived as their core work and its outcomes. 


\section{Discussion}

Our findings provide an initial conceptual development of iQoL as a unique construct. By contributing to a broader and more holistic understanding of research 'productivity' that encompasses the quality of intellectual engagement, our findings could be used to support positive iQoL among stakeholders in academia, including faculty, staff, postdoctoral fellows, students and administrators. Previous research has addressed related concepts, such as quality of work life (QWL) [28], quality of working life [29], or quality of academic worklife (QAWL) [18], that mainly address the various tasks associated with one's professional role. However, our conceptualization of iQoL contributes a unique focus on the intellectual, or 'thinking' aspects of academic life that extend beyond a traditional work boundary. Our concept thus makes a novel contribution to the quality of life literature by focusing specifically on the intellectual aspects of quality of life in academia, in relation to the larger question of work quality more generally.

There is recognition that "Our understanding of humanity and the world in which we live has been greatly enhanced by the insights produced by multidisciplinary research teams and the emergence of interdisciplinary programs within academia" [30] (p. 1). Substantial investments have been made by universities to support the development of interdisciplinary research teams. For instance, within the context of Canadian research-intensive universities, a few examples include the Research Excellence Clusters at the University of British Columbia that has provided over \$4 million annually since 2018 [19], and the Interdisciplinary Development Initiatives at the University of Western Ontario that allocated \$4 million for the 2015-2020 period [31]. The teams funded focus on complex issues requiring innovation, systems thinking, and interdisciplinary collaboration, such as international migration, transformative health and justice, environment and sustainability, and global mental health among many others. Our study of the experiences of faculty, staff, postdoctoral fellows, graduate students, and administrators involved with university-funded interdisciplinary research teams provides empirical findings with respect to the influence of these initiatives upon their iQoL.

While a central aim of creating these university-funded teams is to foster research impact by supporting interdisciplinary collaboration that can otherwise be challenging to achieve in a traditional university structure of siloed faculties and departments, the particular initiative we studied was nonetheless managed in line with a neoliberal rationality that serves to economize everything, including academia [11]. Lorenz detailed the impacts of neoliberalism and managerialism on higher education, explaining that new public management is "characterized by a combination of free market rhetoric and intensive managerial control practices" [32] (p. 600) that draws on concepts of efficiency, accountability, transparency, and quality to assess performance, productivity, and outcomes. Strategies of new public management involve the "decentralization of management control away from the center [... ] through a "new contractualism" that is tied to "new accountability and competitive funding regimes" as well as a shift toward quantifiable output and performance targets" [33] (p. 91). Richter and Hostettler have argued that academic work is now "assessed according to a culture of audit characteristic for neoliberal management of universities that values publication indexes [ ... ]." [34] (p. 493). Practically speaking, Winter et al. reported that public sector reforms in line with these principles led to "increased workloads, time pressures, resource constraints, and feeling overworked, stressed-out and demoralised" [18] (p. 291). They further explained that state decentralization through reductions in public funding for institutions of higher education places a burden on universities to cut costs and secure alterative revenue generating streams, which is further downloaded onto faculty through expectations for work intensification.

Our findings highlight ways that the neoliberal governance of academia and related practices of new public management can negatively impact iQoL by influencing academics' engagement in their core work. Research participants discussed how despite being part of interdisciplinary research teams that enabled creativity and innovation, they were increasingly strained by administrative and bureaucratic burdens related to tasks such as applying for and managing funding, and producing and reporting on outcomes. Traditional measures of academic productivity, including successful grant 
applications and peer-reviewed journal publications, were key expected outcomes of the work of these university-funded interdisciplinary teams. The short timeline of the funding initiative examined, operating on a 12 to 18 month cycle, was shown to create a pressure for timely outcomes to support reapplications that could be challenging to achieve when working across disciplinary boundaries and tackling complex research questions related to wicked social problems. In relation to the primary theme and related sub-themes, participants identified several issues negatively impacting their iQoL that were captured by codes such as 'busy work', 'being stretched too thin', 'obligations to others', 'evaluation metrics', and 'productivity expectations', among others. Approaches to evaluating this university-funded initiative included detailed annual reporting of outputs and outcomes based on specific metrics related to new partnerships and collaborations; education, training, and mentorship initiatives; leveraged funding; knowledge exchange; academic, scholarly and creative outputs; and commitments to equity, diversity, and inclusion. Reflecting such expectations, participants spoke to a sense of increasingly constrained freedom to conduct what they perceived as their core work due to explicit expectations for measurable productivity.

The tension between needing the freedom, space, and time to think that is required for creativity and innovation, and the concurrent need to produce tangible, quantifiable outcomes within the short timeframe expected for renewed funding, creates a pressure within academia that was shown to shape participants' iQoL. Our findings highlight a complex web of factors that can both positively and negatively affect people's potential to engage in what they view as their core work and to achieve the desired outcomes of that work. These factors include the social and relational climate that inform people's inter-personal work environment and their daily social interactions, the broader institutional environment and structure, such as policies and procedures governing their work, as well as the expectations they face and the resources that are available to them within a high pressure environment that is managed through a complex bureaucracy. Our research echoes findings by Villeneuve and colleagues [35] who have also recently explored the relationship between interdisciplinary team building and wicked problems. Similar to our theme on the importance of a positive social and relational climate for supporting $\mathrm{iQoL}$, they found that the nature of interdisciplinary interactions could generate advantages or challenges as related to the intersubjective relationships between team members [35]. Building on our findings, universities could promote supportive social and relational climates, ensure that adequate time is given and infrastructure is in place to conduct research, and provide adequate resources, among other initiatives to support iQoL among its employees and students. For example, the slow professor movement [36] has been proposed as a response to work intensification that can attend to the mismatch identified between institutional agendas and individuals' perceptions of what they understand and value as their core work.

As a case study undertaken within a single university context, our research is not without limitations. In seeking to understand the experiences of those engaged in interdisciplinary research teams, our current conceptualization of iQoL does not capture the experiences of those in academia who are working in more traditional disciplinary structures. Future research should examine whether they would identify similar factors as influencing their iQoL. Further, it would be useful to compare our findings with research examining interdisciplinary initiatives at other universities and in other countries. Finally, developing reliable and valid measures to capture the iQoL experience within and across institutions will help set a national environment that fosters successful innovation and collaboration amongst academic students, staff, and faculty.

\section{Conclusions}

The ongoing and increasing managerialization of academia [10], concomitant with expectations that academic research be useful for tackling complex social problems, reflect a paradox characterizing higher education that has being undergoing neoliberal reforms "in relation to quality assurance, managerialist practices, accountability and performativity" [14] (p. 175). In advocating for a slow professor movement, Berg and Seeber [36] criticized the increased speed and expected efficiency of 
academic work due to its potential negative consequences on scholarship and education. Our work ultimately highlights the potential negative implications of increasing expectations to ensure neoliberal accountability, such as increased administrative duties and pressure to produce measurable outcomes, upon the iQoL of university faculty, staff, and graduate students who obtain funding to support the interdisciplinary and innovative approaches that are needed to tackle wicked social problems.

Author Contributions: The focus groups were moderated by S.H., J.M., S.B., and L.H. Individual interviews were conducted by the S.B. and/or L.H. All authors contributed to study conceptualizations, data analysis, and interpretation. All authors have read and agreed to the published version of the manuscript.

Funding: This research received no external funding.

Acknowledgments: We would like to thank all of the participants for the time and insights they contributed to this study, as well as Designing for People (https://dfp.ubc.ca/) for their support of this research.

Conflicts of Interest: The authors declare no conflict of interest.

\section{References}

1. Wicks, A.; Jamieson, M. New Ways for Occupational Scientists to Tackle "Wicked Problems" Impacting Population Health. J. Occup. Sci. 2014, 21, 81-85. [CrossRef]

2. Alrøe, H.F.; Noe, E. Second-order science of interdisciplinary research: A polycular framework for wicked problems. Constr. Found. 2014, 10, 65-76.

3. Dentoni, D.; Bitzer, V. The role(s) of universities in dealing with global wicked problems through multi-stakeholder initiatives. J. Clean. Prod. 2015, 106, 68-78. [CrossRef]

4. Huot, S.; Raanaas, R.K.; Rudman, D.L.; Grimeland, J. Integrating occupational and public health sciences through a cross-national educational partnership. J. Occup. Sci. 2018, 25, 431-441. [CrossRef]

5. Rittel, H.W.J.; Webber, M.M. Dilemmas in a general theory of planning. Policy Sci. 1973, 4, 155-169. [CrossRef]

6. Blackman, T.; Greene, A.; Hunter, D.J.; McKee, L.; Elliott, E.; Harrington, B.; Marks, L.; Williams, G. Performance Assessment and Wicked Problems: The Case of Health Inequalities. Public Policy Adm. 2006, 21, 66-80. [CrossRef]

7. Brenner, W.; Uebernickel, F. (Eds.) Design Thinking for Innovation: Research and Practice; Springer: New York, NY, USA, 2016.

8. Frank, G.; Muriithi, B.A.K. Theorising social transformation in occupational science: The American Civil Rights Movement and South African struggle against apartheid as 'Occupational Reconstructions'. South Afr. J. Occup. Ther. 2015, 45, 11-19. [CrossRef]

9. Evans, B.; Richmond, T.; Shields, J. Structuring Neoliberal Governance: The Nonprofit Sector, Emerging New Modes of Control and the Marketisation of Service Delivery. Policy Soc. 2005, 24, 73-97. [CrossRef]

10. Cannizzo, F. Tactical evaluations: Everyday neoliberalism in academia. J. Sociol. 2018, 54, 77-91. [CrossRef]

11. Berg, L.D.; Huijbens, E.H.; Larsen, H.G. Producing anxiety in the neoliberal university. Can. Geogr. 2016, 60, 168-180. [CrossRef]

12. Hawkins, R.; Manzi, M.; Ojeda, D. Lives in the making: Power, academia and the everyday. Int. E-J. Crit. Geogr. 2014, 13, 328-351.

13. Carpenter, C.R.; Cone, D.C.; Sarli, C.C. Using Publication Metrics to Highlight Academic Productivity and Research Impact. Acad. Emerg. Med. 2014, 21, 1160-1172. [CrossRef] [PubMed]

14. Raaper, R. Academic perceptions of higher education assessment processes in neoliberal academia. Crit. Stud. Educ. 2015, 57, 1-16. [CrossRef]

15. Sabagh, Z.; Hall, N.C.; Saroyan, A. Antecedents, correlates and consequences of faculty burnout. Educ. Res. 2018, 60, 131-156. [CrossRef]

16. Slottje, D.J.; Scully, G.W.; Hirschberg, J.G.; Hayes, K.J. Measuring the Quality of Life Across Countries: A Multidimensional Analysis; Routledge: London, UK, 2019.

17. Karimi, M.; Brazier, J. Health, Health-Related Quality of Life, and Quality of Life: What is the Difference? PharmacoEconomics 2016, 34, 645-649. [CrossRef]

18. Winter, R.; Taylor, T.; Sarros, J. Trouble at Mill: Quality of academic worklife issues within a comprehensive Australian university. Stud. High. Educ. 2000, 25, 279-294. [CrossRef] 
19. Coca, E.L.D.F. Universidades e o mercado institucional de alimentos: O exemplo da University of British Columbia (UBC), em Vancouver, no Canadá. Redes 2019, 24, 45-61. [CrossRef]

20. Merriam, S.B. Qualitative Research and Case Study Applications in Education, 2nd ed.; Jossey-Bass Publishers: San Francisco, CA, USA, 1998.

21. Harrison, H.; Birks, M.; Franklin, R.; Mills, J. Case study research: Foundations and methodological orientations. Forum Qual. Soc. Res. 2017, 18, 19.

22. Lambert, S.D.; Loiselle, C.G. Combining individual interviews and focus groups to enhance data richness. J. Adv. Nurs. 2008, 62, 228-237. [CrossRef]

23. Bennet, K. Interviews and focus groups. In Doing Cultural Geography; Sage: London, UK, 2002; pp. 151-165.

24. Cameron, J. Focusing on the focus group. In Qualitative Methods in Human Geography, 3rd ed.; Oxford University Press: Don Mills, ON, Canada, 2010; pp. 152-172.

25. Longhurst, R. Semi-structured interviews and focus groups. In Key Methods in Geography; Sage: London, UK, 2010; pp. 103-115.

26. Cloke, P.; Cook, I.; Crang, P.; Goodwin, M.; Painter, J.; Philo, C. Practicing Human Geography; Sage: London, UK, 2004.

27. Braun, V.; Clarke, V. Using thematic analysis in psychology. Qual. Res. Psychol. 2006, 3, 77-101. [CrossRef]

28. Mohammadi, S.; Karupiah, P. Quality of work life and academic staff performance: A comparative study in public and private universities in Malaysia. Stud. High. Educ. 2019, 1-15. [CrossRef]

29. Fontinha, R.; Van Laar, D.; Easton, S. Quality of working life of academics and researchers in the UK: The roles of contract type, tenure and university ranking. Stud. High. Educ. 2016, 43, 786-806. [CrossRef]

30. VanderPlaat, M. Societies: An Open Access Journal of Social Sciences and Humanities. Societies 2011, 1, 1-2. [CrossRef]

31. University of Western Ontario. Interdisciplinary Development Initiatives. Available online: https://www. uwo.ca/facultyrelations/academic_planning/idi/index.html (accessed on 18 December 2019).

32. Lorenz, C. If You're So Smart, Why Are You under Surveillance? Universities, Neoliberalism, and New Public Management. Crit. Inq. 2012, 38, 599-629. [CrossRef]

33. Peters, M.A.; Liu, T.-C.; Ondercin, D.J. The Pedagogy of the Open Society: Knowledge and the Governance of Higher Education; Springer Science and Business Media LLC: Boston, MA, USA, 2012.

34. Richter, M.; Hostettler, U. Conducting commissioned research in neoliberal academia: The conditions evaluations impose on research practice. Curr. Sociol. 2015, 63, 493-510. [CrossRef]

35. Villeneuve, D.; Durán-Rodas, D.; Ferri, A.; Kuttler, T.; Magelund, J.; Mögele, M.; Nitschke, L.; Servou, E.; Silva, C. What is Interdisciplinarity in Practice? Critical Reflections on Doing Mobility Research in an Intended Interdisciplinary Doctoral Research Group. Sustainability 2019, 12, 197. [CrossRef]

36. Berg, M.; Seeber, B.K. The Slow Professor: Challenging the Culture of Speed in the Academy; University of Toronto Press: Toronto, ON, Canada, 2016.

(C) 2020 by the authors. Licensee MDPI, Basel, Switzerland. This article is an open access article distributed under the terms and conditions of the Creative Commons Attribution (CC BY) license (http://creativecommons.org/licenses/by/4.0/). 